\title{
Microskills Training: A Model for Teaching Verbal Processing Skills in Music Therapy
}

\author{
Lori Fogus Gooding ${ }^{1 *}$ \\ 1 College of Music, Florida State University, United States \\ *lgooding@fsu.edu
}

Received: 20 October 2016 ; Accepted: 23 January 2017 ; Published: 1 March 2017

\begin{abstract}
Music therapy scholars have suggested that verbal processing is widely integrated into music therapy practice, though specific implementation varies based on the therapeutic approach and the clients' level of functioning. Results from music therapy studies have suggested that clients find verbal processing both important and useful, yet the development of verbal processing skills can be difficult for music therapists and music therapy students. Given the complexity of the skills needed, inclusion of a model or framework may help focus and organize skill development. One model that may have wide utility among music therapy practice is the microskills model (microcounseling). Microcounseling is built upon ethical and cultural competence, addresses skills in a hierarchical manner, and can be combined with a number of theoretical approaches. Research shows that this model has been successfully translated into 21 languages, used in a range of helping professions, and taught in both traditional and self-instruction formats. Perhaps most importantly, the model initially focuses on skills needed by all music therapists, regardless of theoretical orientation, and then progresses to skills needed to effectively facilitate common music therapy interventions like song discussion. Combining this model with other elements of music therapy education may better promote skill development and guide music therapists in skill usage.
\end{abstract}

Keywords: verbal processing, counseling skills, music therapy, microskills

\section{Verbal Processing in Music Therapy}

Nolan (2005) defined verbal processing in music therapy as the "talking that facilitates the therapeutic process during, and in response to, music making or music listening" (p. 18). Typically, music interventions are used to establish a context in which change can occur (Austin, 1996; Gardstrom, 2001), and verbal techniques are implemented to encourage clients to respond verbally (Nolan, 2005). Musical interventions associated with verbal processing in the music therapy literature include improvisation (Gardstrom, 2001), song writing (Dalton \& Krout, 2006; Jones, 2005; Thompson, Grocke, \& Dileo, 2016), lyric analysis/song discussion (Dvorak, 2016; Eyre \& Lee, 2015; Gardstrom \& Hiller, 2010; Jones, 2005), and Guided Imagery and Music (GIM) (Beck, Hansen, \& Gold, 2015). Verbal techniques cited in the literature include basic counseling skills (Grocke \& Wigram, 2007), verbal response skills (Gardstrom, 2001), and microskills (Gooding, 2014). Specific skills used by music therapists have included active listening, open-ended questions, paraphrasing, probes, providing choices, silence, 
nonverbal communication, and clarifying. These skills have been used to facilitate verbal processing of thoughts, behaviors, and emotions (Amir, 1999; Gardstrom, 2001; Grocke \& Wigram, 2007; Linblad, 2016).

Differing theoretical orientations influence how individual music therapists incorporate verbal processing (i.e., discussion, counseling skills) into music therapy practice (Choi, 2008; Darrow, 2008). Though all music therapists employ musical experiences to address clients' needs, the amount of music-and conversely verbal processingused during therapeutic interactions varies based on the music therapist's approach (Choi, 2008). For music therapists practicing from a music- centered or music as therapy perspective, music is the catalyst for change. Music serves as the medium through which therapeutic issues are accessed, addressed, and resolved (Ansdell, 1999; Bruscia, 1998a; Gardstrom, 2001; Linblad, 2016), and verbal components are typically limited to social interactions and assessment of the therapeutic progress (Gardstrom, 2001; Grocke \& Wigram, 2007; Guerrero, Marcus, \& Turry, 2015). However, some musiccentered models like Analytic Music Therapy incorporate verbal interventions to communicate ideas, share insight, and make interpretations (Amir, 1999; Bruscia, 1988).

In music in therapy models, therapists place equal importance on musical and verbal interventions (Amir, 1999). Therapists practicing from this perspective use music interventions to explore and discuss an individual's extra-musical experiences (Gardstrom, 2001). Verbal processing might be used to increase awareness, understanding, or insight; provide opportunities for transfer from musical settings to everyday settings; or allow individuals to make personal connections between verbal discourse and life events (Gardstrom, 2001; Nolan, 2005; Pitts \& Silverman, 2015; Salmon, 2008). Verbal processing may also promote increased awareness of the present moment (Lindblad, 2016) or facilitate psychoeducation (Silverman, 2009). It can help the music therapist determine what learning and/or understanding has occurred during group exercises (Dvorak, 2016) and may play an important role in communicating therapeutic progress to parents and other professionals (Baek, 2007).

Limited information has been published regarding the implementation of verbal processing in music therapy (Amir, 1999; Lindblad, 2016; Nolan, 2005), and the existing literature primarily focuses on when and with whom verbal processing is used. Verbal processing in music therapy occurs before, during, and/or after musical experiences (Amir, 1999). The combination of music and verbal processing is based on consumer objectives and fluctuates both within and between sessions (Silverman, 2015). The client's level of functioning also appears to influence how-and when-verbal processing is incorporated (Hadsell, 1974). For example, when working with individuals for whom verbal processing would be ineffective or undesirable, sessions are often music-centered (Bruscia, 2006) and contain little-or no-verbal processing. For individuals who are seriously ill or disorganized, verbal processing may be included but be activity focused, with little emphasis on insight (Wheeler, 1983; 1987). Conversely, the use of verbal processing may increase as psychotic symptoms abate (Hadsell, 1974) and verbal processing may become more prevalent as clients' abilities to engage increase and/or the depth of the goals increase (Bruscia, 1998; Wheeler, 1983). Likewise, the amount of music incorporated may decrease or fluctuate as verbal processing increases (Silverman, 2015).

Guidelines for the use of verbal processing in terms of timing, indications, and considerations do appear in the music therapy literature, but they too are limited (Amir, 1999). Nolan (2005) and Amir (1999) discussed the use of specific elements or techniques like silence within verbal processing. Gardstrom and Hiller (2010) addressed other considerations like the use of probes and decisions related to music delivery (live vs. recorded music, playing the music more than once, etc.) in their writing regarding song discussion procedures. Grocke and Wigram (2007) provided procedural instructions for song discussion as well as strategies for responding to clients. Dvorak (2016) provided a conceptual framework for lyric analysis to assist music therapy students and beginning clinicians in planning, implementing, and evaluating lyric analysis interventions. 


\section{Research on Verbal Processing in Music Therapy}

A systematic review of music therapy practice with acute adult psychiatric in-patients conducted by Carr and Odell-Miller (2013) showed that verbal reflection was used in 63 of 96 studies analyzed; this represents a 65\% usage rate for verbal processing. Likewise, results from other studies have provided support for increased use of verbal processing with higher functioning clients (Lindblad, 2016), as well support for the use of verbal processing to respond to specific therapeutic situations and/or needs like clients' anger (Jackson, 2010). There is also some indication that clients find verbal processing in music therapy useful. Results of an investigation of music therapists working in post-stroke rehabilitation showed that both the therapists and clients viewed the interaction (i.e., discussion) with clients as the most important factor in keeping sessions therapeutic (Forsblom \& Ala-Ruona, 2012). Paulander's study (as cited in Lindblad, 2016) showed that verbal processing in music therapy enables clients to process, understand, and give meaning to their musical experiences. Gavriedlidou and Odell-Miller (2017) concluded that verbal expression is a comment component in pivotal moments (i.e., turning points) in music therapy. Finally, Goldberg, McNeil, and Binder (1988) found that clients viewed music therapy to be helpful in much the same way that verbal group therapy is helpful.

\section{Education and Training}

Use of verbal processing within the field of music therapy varies, but all music therapists must be able to employ active listening, provide verbal guidance, facilitate transfer of therapeutic progress, mediate problems between clients, and analyze lyrics (CBMT, 2015). Gardstrom (2001) argued that development of such skills can be challenging for music therapy students. Internship supervisors have likewise expressed concerns about students' development of counseling skills (Knight, 2008), and pre-professional students identified counseling skills training as an area that was weak or underdeveloped (Clements-Cortes, 2015). Music therapy students have also expressed the desire for improved counseling skills training, particularly before being placed in challenging settings like hospice (Pitts \& Cevasco, 2013). Professionals too are interested in developing improved verbal processing skills; according to the American Music Therapy Association, counseling or verbal processing skills are a frequently requested continuing education topic (AMTA National Conference, 2015).

Given that music therapists desire opportunities to develop or improve verbal processing skills, it is important to identify current training practices. A review of the literature revealed no universal model or framework for training, though specific training suggestions have been made. Gardstrom (2001) advocated for training of undergraduate students in basic counseling skills and called for the inclusion of specific techniques found in Okun \& Kantrowitz's (2014) helping model. Grocke and Wigram (2007) called for the use of basic counseling skills and outlined key components for music therapy practice in their text for clinicians, educators, and students. The authors provided exercises for practice, vignettes for study, and specific strategies for use when implementing receptive methods like relaxation. Silverman (2015) suggested using the Continuum Model to help students understand both the role and ratio of music and verbal processing within music therapy practice, while Barry and O'Callaghan (2009) advocated for the use of reflexive journal writing as a tool to facilitate development of musically supported counseling, validation, and other music therapy practice skills. Inclusion of a framework or model may help students and beginning professionals identify basic skills needed during verbal processing and guide educators and internship directors when providing verbal processing skills instruction. Additionally, use of a model may guide continuing education and enable music therapists to effectively implement verbal processing skills. 


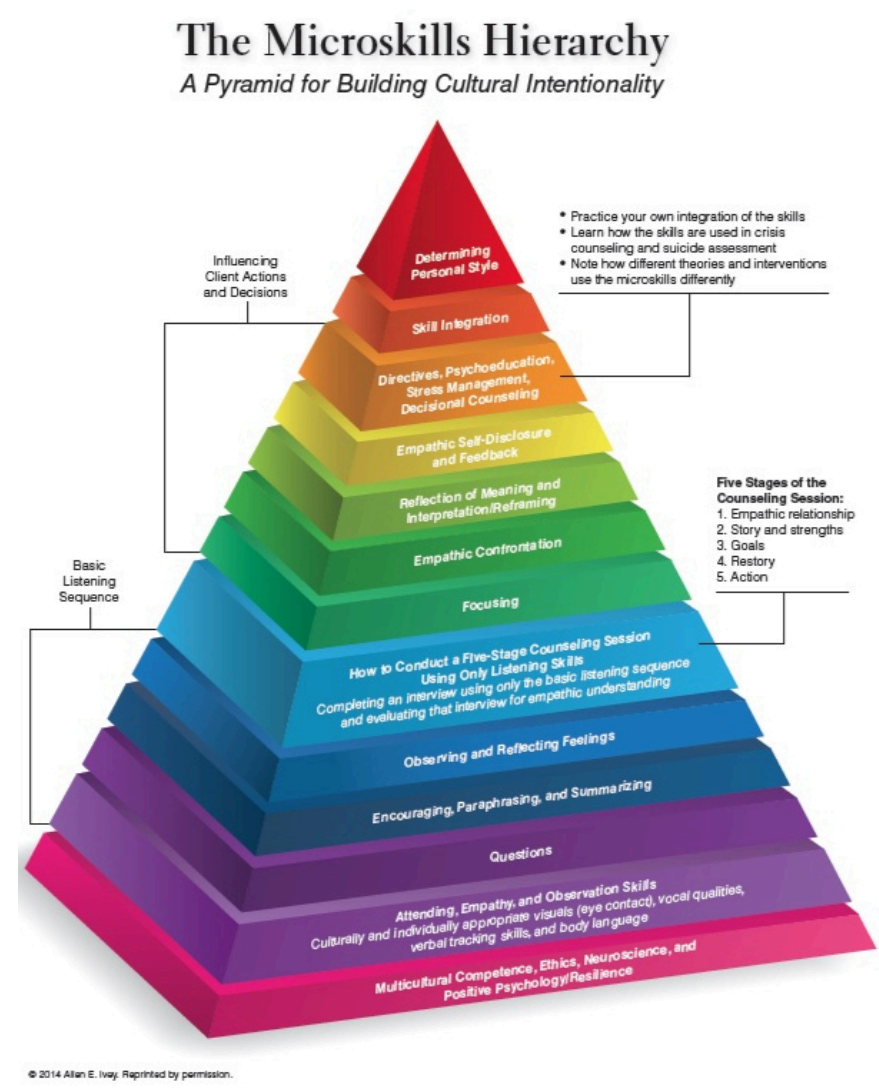

Figure 1. Microskills Hierarchy

Reprinted with permission.

\section{The Microskills Model}

Microskills are individual communication skill units that allow helping professionals to interact intentionally with clients (Ivey \& Ivey, 2014). Microskills training, also known as microcounseling, has been identified as the primary pedagogy in counselor education; the model is widely used and well researched, with a strong empirical base supporting its utility (Daniels, 2003; Ridley, Mollen, \& Kelly, 2011). Microcounseling can be considered both a training system and practical framework; it serves as a training model for teaching discrete skills and a way to conceptualize the therapeutic process (Daniels \& Ivey, 2007). Because it focuses on fundamental skills for effective helping without imposing any theoretical modality or worldview (Ivey \& Daniels, 2016), microskills can be integrated with other theories that focus on promoting client growth and development. This includes cognitive behavioral techniques, feminist therapy, humanistic therapy, and developmental therapy, as well as other individual and group approaches (Daniels \& Ivey, 2007).

Ethics and multicultural competence serve as the foundation of the microskills mod$\mathrm{el}$, and skills are developed in a hierarchical manner with each skill set building upon previous skills. Attending, empathy, and observation skills are the first to be addressed; these skills include eye contact (visuals), vocal qualities, verbal tracking skills, and use of body language. The next skills addressed include asking questions, encouraging, paraphrasing, summarizing, and observation and reflection of feelings; these skills form the remainder of the basic listening sequence (BLS). Influencing skills, which include focusing, feedback and confrontation, are more advanced skills; they are addressed after the basic listening sequence has been mastered. After all skills have been addressed, the model focuses on development of one's personal style (Ivey \& Ivey, 2014). These skills, regardless of level, are implemented within a culturally and contextually appropriate context grounded in neuroscience and positive psychology (Ivey \& Daniels, 2016). See Figure 1 for more information on the Microskills Hierarchy. 


\section{Microskills Training}

Microskills training originated as an approach to develop counseling skills in prepracticum beginning counselors (Ivey, Normington, Miller, Morrill, \& Haase, 1968). Microskills training involves a four-step training process: (1) theoretical instruction, (2) modeling, (3) practicing, and (4) feedback (Daniels, Rigazio-DiGilio, \& Ivey, 1997). Microskills training is currently used in a variety of techniques courses to introduce students to professional counseling skills (Hall \& Richardson, 2014; Kuntze, van der Mollen, \& Born, 2009). Microskills are taught in a number of different ways, including role-play, discussion, review of video excerpts, and supervisor feedback (Ivey \& Daniels, 2016). The skills are then reinforced across the curriculum, with special emphasis during practicum and internship (Hall \& Richardson, 2014). Traditionally, microskills instruction has utilized a trainer for all training aspects, but self-instructional models (e.g., self-instructional books paired with supervisor-led feedback) have also been developed to reduce trainer time (Schönrock-Adema, Van der Molen, \& van der Zee, 2009). Results have shown that the microcounseling training method is effective in both traditional and self-instruction formats and that students perform best on basic skills (Ivey \& Daniels, 2016; Schönrock-Adema et al., 2009). Skill mastery appears to be related to both supervision and amount of training (Schönrock-Adema et al., 2009).

\section{Implications for Music Therapy Training}

Music therapy training around the globe is diverse, and the skills needed for competent practice continue to change as both the field and its knowledge base expand (Choi, 2008; Goodman, 2011; Sundar, 2008). Students have expressed concerns about having sufficient knowledge, skills, and competence to work with clients (Baker \& Krout, 2009). It has been argued that methods and techniques are best introduced during coursework (Goodman, 2011), yet concerns have been expressed about incorporating additional concepts into the already full music therapy curriculum. Similarly, there are also concerns about students' abilities to access clinical and academic training opportunities (Clark \& Thompson, 2016; Wylie, Hunter, \& Snell, 2013). Therefore it is important to find effective and economical ways to incorporate specific skills into music therapy training.

Calls for the inclusion of group dynamics and/or verbal techniques in music therapy coursework have appeared periodically (Gardstrom, 2001; Goodman, 2011; Maranto \& Bruscia, 1988). However, as recently as 2015 students identified counseling skills training as an area that is weak or underdeveloped in the music therapy curriculum (Clements-Cortes, 2015). This suggests that there is still a need for inclusion or refinement of such skills in the music therapy curriculum. Microskills training was designed to teach the basic skills of counseling in a short period of time (Ivey et al., 1968). As a result, the microskills model may provide a framework for verbal processing instruction that facilitates growth without increasing the educational burden in music therapy programs. The hierarchical nature of the microskills model allows for discrete teaching of specific skills, thereby allowing instruction to occur across time and multiple courses. Furthermore, the ability to teach skills discretely would also allow educators to focus on elements relevant to their program's theoretical orientation, specialty area, or students' levels of experience. The use of both traditional and self-instructional teaching practices in microskills training (Ivey \& Daniels, 2016; Schönrock-Adema et al., 2009) may also allow for reduced class instruction time without reduced skill attainment. Likewise, the practice of transferring microskills knowledge to clinical settings for further development is consistent with the current educational and clinical training model employed in music therapy (Goodman, 2011). This too suggests that the model may be easily accommodated within the music therapy curriculum. Microskills training may even be effectively integrated into on-line or distance education and/or continuing education. Given the pressures that universities face to increase distance learning opportunities, and the growing market for online continuing education (Vega 


\section{Basic skills progress to more complex skills and skill integration}
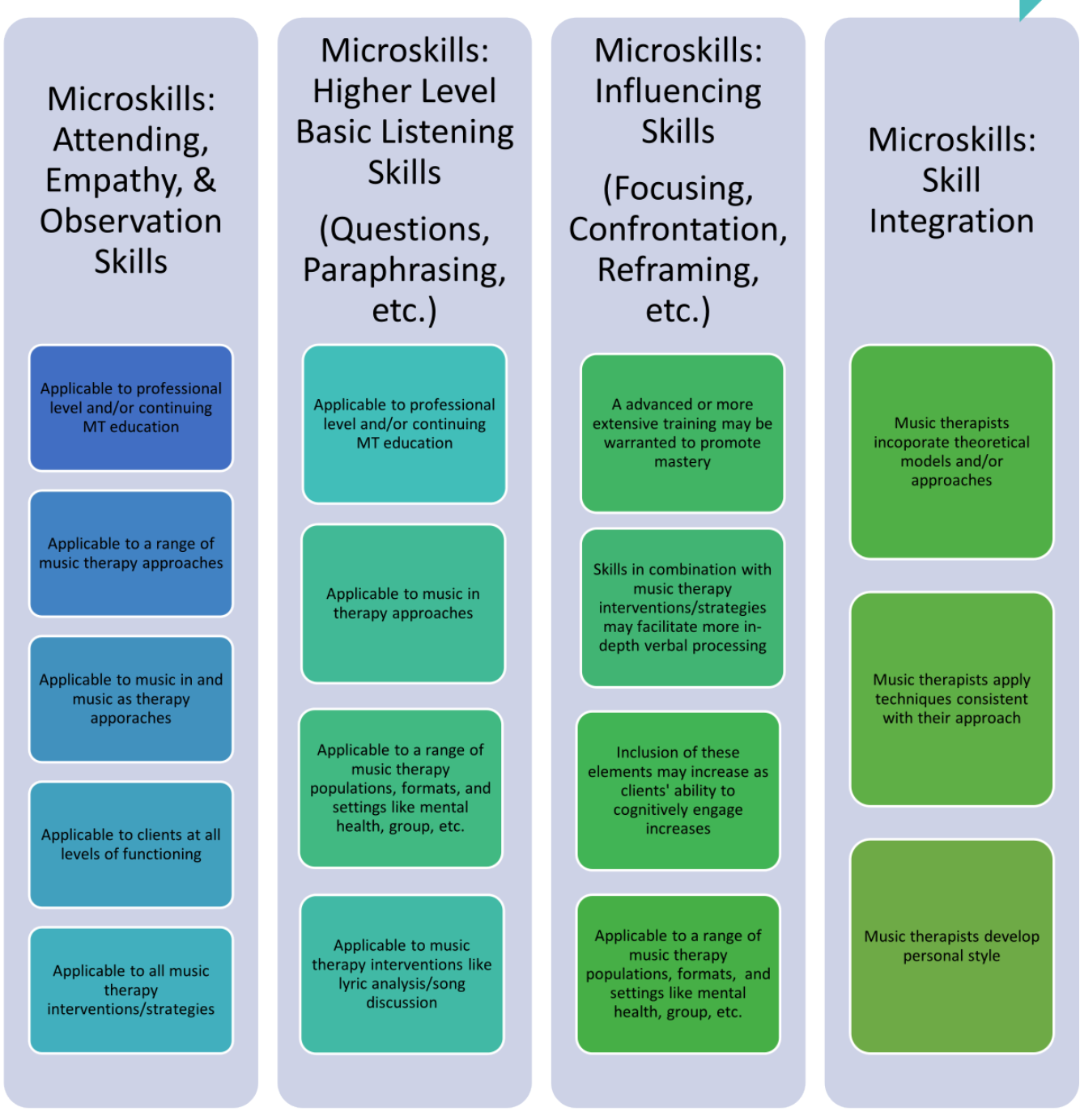

Cultural and Ethical Competence Serve As Foundation

Figure 2. Microskills and related music therapy constructs.

\& Keith, 2012), teaching strategies that lend themselves to multiple formats may have the most potential for inclusion.

Fundamentally, microcounseling is rooted in ethical and culturally competent practice. It has been translated into 21 languages and adapted to emphasize multicultural variation in communication (Ivey \& Daniels, 2016). Multicultural competence is increasingly important in the field of music therapy (Young, 2016), and use of a model that incorporates cultural diversity may increase its utility. Microskills training imparts skills needed to verbally process text, musical elements and/or clients' associations, and development of these skills may improve the quality of music therapy interventions like song discussion. Equally as important, the skills learned in the microskills model are applicable to group and individual experiences, to a variety of settings including hospice, medical, and mental health, and to communication with parents and colleagues (Baek, 2007; Gooding, 2014; Nolan, 2005; Pitts \& Cevasco, 2013; Pitts \& Silverman, 2015). The adaptability and flexibility of this model lends itself to inclusion 
in music therapy training and practice. See Figure 2 for additional information on applying the microskills model to music therapy training and practice.

\section{Conclusion}

Communication is a fundamental component of music therapy practice, and verbal processing can be an effective tool to facilitate communication with clients, parents, and colleagues. Students and professionals have expressed a desire for additional training in verbal processing skills, and scholars have called for inclusion of basic counseling skills training in music therapy education. However, development of such skills can be challenging, especially given the already strained nature of the music therapy curriculum.

The ideas presented in this paper provide a basis for the use of the Microskills Model in music therapy. The a-theoretical nature of the model combined with its adaptability to music therapy education suggests it could be easily integrated without adding additional burden to the curriculum. As music therapy continues to expand, it is important that we develop both efficient and effective ways to address the competencies needed for successful music therapy practice. It is hoped that this model will provide a possible framework from which verbal processing skills could be taught. It is also hoped that it will stimulate discussion regarding verbal processing in music therapy, both in terms of its usage and how to best facilitate the skills needed for implementation. Music therapy clinicians and educators are encouraged to consider this framework-and others-to facilitate skill development and provide a practical framework to guide verbal processing pedagogy.

\section{References}

AMTA National Conference (2015). CMTE spotlight: Counseling skills in music therapy. Retrieved from http://amtanationalconference.com/cmte-spotlight-counseling-techniquesin-music-therapy/

Amir, D. (1999). Musical and verbal interventions in music therapy: A qualitative study. Journal of Music Therapy, 36, 144-176, http://dx.doi.org/10.1093/jmt/36.2.144.

Ansdell, G. (1999). Music therapy as discourse and discipline: A study of "music therapist's dilemma. City University of London: London.

Austin, D. S. (1996). The role of improvised music in psychodynamic music therapy with adults. Music Therapy, 14, 29-43, https://doi.org/10.1093/mt/14.1.29,.

Baek, H. S. (2007). Surviving as a music therapist. A World Forum for Music Therapy, 17(1), http://dx.doi.org/10.15845/voices.v7i1.466.

Baker, F., \& Krout, R. E. (2009). Collaborative peer lyric writing during music therapy training: A tool for facilitating students' reflections about clinical practicum experiences. Nordic Journal of Music Therapy, 20, 62-89, http://dx.doi.org.proxy.lib.fsu.edu/10.1080/ 08098131.2010.486132.

Barry, P., \& O'Callaghan, C. (2009). A tool for music therapy student clinical practice development. Nordic Journal of Music Therapy, 17, 55-66, http://dx.doi.org/10.1080/ 08098130809478196.

Beck, B. D., Hansen, A. M., \& Gold, C. (2015). Coping with work-related stress through Guided Imagery and Music (GIM): Randomized controlled trial. Journal of Music Therapy, 52, 323-352, https://dx.doi.org/10.1093/jmt/thv011.

Bruscia, K. E. (1988). A survey of treatment procedures in improvisational music therapy. Psychology of Music, 16, 10-24, https://doi.org/10.1177/0305735688161002.

Bruscia, K. E. (1998). The dynamics of music psychotherapy. Gilsum, NH: Barcelona.

Bruscia, K. (2006). Case studies in music therapy. Gilsum, NH: Barcelona.

Carr, C., \& Odell-Miller, H. (2013). A systematic review of music therapy practice and outcomes with acute adult psychiatric in-patients. PLOS One, 8, e70252, https://dx.doi.org/ 10.1371/journal.pone.0070252. 
Certification Board for Music Therapists (CBMT) (2015). Board Certification Domains. Retrieved from file:///C:/Users/ldg07c.FSU/Downloads/ CBMT_Board_Certification_Domains_2015\%20(2).pdf

Choi, B. C. (2008). Awareness of music therapy practices and factors influencing specific theoretical approaches. Journal of Music Therapy, 45, 93-109, https://dx.doi.org/10.1093/ jmt/45.1.93.

Clark, I. N., \& Thompson, G. A. (2016). Reflections on music therapy training within elearning education contexts. Voices: A World Forum for Music Therapy, 16(1), http://dx.doi.org/10.15845/voices.v16i1.835.

Clements-Cortes, A. (2015). A study of pre-professionals' understanding of the Canadian music therapy internship. Journal of Music Therapy Perspectives, 52, 221-257, http://dx.doi.org/ 10.1093/jmt/thv006.

Dalton, T. A., \& Krout, R. E. (2006). The grief song-writing process with bereaved adolescents: An integrated grief model and music therapy protocol. Music Therapy Perspectives, 24, 94-107, https://dx.doi.org/10.1093/mtp/24.2.94.

Daniels, T. (2003). Overview of research on microcounseling: 1967-present. In A. E. Ivey \& M. B. Ivey (Eds.), Intentional interviewing and counseling: Your interactive resource. Pacific Grove, CA: Brooks/Cole.

Daniels, T., \& Ivey, A. (2007). Microcounseling: Making skills training work in a multicultural world. Springfield, IL: Charles C Thomas Publisher, LTD.

Daniels, T., Rigazio-DiGilio, S. A., \& Ivey, A. (1997). Microcounseling: A training and supervision paradigm for the helping professions. In C. E. Watkins (Ed.), Handbook of psychotherapy supervision (pp. 277-295).

Darrow, A. (Ed.). (2008). Introduction to approaches in music therapy (2nd ed.). Silver Spring, MA: American Music Therapy Association, Inc.

Dvorak, A. (2016). A conceptual framework for group processing of lyric analysis interventions in music therapy mental health practice. Music Therapy Perspectives, Advance online publication, https://dx.doi.org/10.1093/mtp/miw018.

Eyre, L., \& Lee, J. H. (2015). Mixed-methods survey of professional perspectives of music therapy practice in mental health. Music Therapy Perspectives, 33, 162-181, https://dx.doi.org/10.1093/mtp/miv034.

Forsblom, A., \& Ala-Ruona, E. (2012). Professional competences of music therapists working in post-stroke rehabilitation. Voices: A World Forum for Music Therapy, 12(3), http://dx.doi.org/10.15845/voices.v12i3.647.

Gardstrom, S. C. (2001). Practical techniques for the development of complementary skills in musical improvisation. Music Therapy Perspectives, 19, 82-87, https://doi.org/10.1093/mtp/ 19.2.82.

Gardstrom, S. C., \& Hiller, J. (2010). Song discussion as music psychotherapy. Music Therapy Perspectives, 28, 147-156, https://dx.doi.org/10.1093/mtp/28.2.147.

Gavriedlidou, M., \& Odell-Miller, H. (2017). An investigation of pivotal moments in music therapy in adult mental health. The Arts in Psychotherapy, 52, 50-62, http://dx.doi.org/ 10.1016/j.aip.2016.09.006.

Gooding, L. F. (2014). Music therapy and the psychosocial care of medical patients. In L. F. Gooding (Ed.), Medical music therapy: Building a comprehensive program (pp. 213-226). Silver Spring, MD: American Music Therapy Association.

Goodman, K. D. (2011). Music therapy education and training: From theory to practice. Springfield, IL: Charles C Thomas.

Goldberg, F. S., McNeil, D. E., \& Binder, R. L. (1988). Therapeutic factors in two forms of inpatient group psychotherapy: Music therapy and verbal therapy. Group, 12, 145-156, https://dx.doi.org/10.1007/BF01456564.

Grocke, D., \& Wigram, T. (2007). Receptive methods in music therapy: Techniques and clinical applications for music therapy clinicians, educators and students. London: Jessica Kingsley Publishers. 
Guerrero, N., Marcus, D., \& Turry, A. (2015). Nordoff-Robbins music therapy. In B. Wheeler (Ed.), Music Therapy Handbook (pp. 183-195). New York: Guilford Press.

Hadsell, N. (1974). A sociological theory and approach to music therapy practice with adult psychiatric consumers. Journal of Music Therapy, 11, 113-124, http://dx.doi.org/10.1093/ jmt/11.3.113.

Hall, K. G., \& Richardson, E. D. (2014). Multicultural microskills: Implementation on an existing design. Journal for International Counselor Education, 6, 75-89.

Ivey, A. E., \& Daniels, T. (2016). Systematic interviewing microskills and neuroscience: Developing bridges between the fields of communication and counseling psychology. International Journal of Listening, 30(3), 99-119, https://dx.doi.org/10.1080/ 10904018.2016.1173815.

Ivey, A. E., \& Ivey, M. B. (2014). Intentional interviewing and counseling: Facilitating client development in a multicultural society (8th ed.). Pacific Grove, CA: Brooks/Cole.

Ivey, A. E., Normington, C. J., Miller, D. C., Morrill, W. H., \& Haase, R. E. (1968). Microcounseling and attending behavior: An approach to prepracticum counselor training. Journal of Counseling Psychology, 15, 1-12, http://dx.doi.org/10.1037/h0026129.

Jackson, N. A. (2010). Models of response to client anger in music therapy. The Arts in Psychotherapy, 37, 46-55, http://dx.doi.org/10.1016/j.aip.2009.09.006.

Jones, J. D. (2005). A comparison of songwriting and lyric analysis techniques to evoke emotional change in a sings session with people who are chemically dependent. Journal of Music Therapy, 42, 94-110, https://dx.doi.org/10.1093/jmt/42.2.94.

Knight, A. J. (2008). Music therapy internship supervisors and preinternship students: A comparative analysis of questionnaires. Journal of Music Therapy, 45, 75-92, https://dx.doi.org/10.1093/jmt/45.1.75.

Kuntze, J., van, H. T., \& Born, M. P. (2009). Increase in counseling communication skills after basic and advanced microskills training. The British Journal of Educational Psychology, 79, 175-188, https://dx.doi.org/10.1348/000709908X313758.

Linblad, K. (2016). Verbal dialogue in music therapy: A hermeneutical analysis of three music therapy sessions. Voices: A World Forum for Music Therapy, 16(1), http://dx.doi.org/ 10.15845/voices.v16i1.842.

Maranto, C. D., \& Bruscia, K. E. (1988). Methods of teaching and training the music therapist. PA: Temple University.

Nolan, P. (2005). Verbal processing within the music therapy relationship. Music Therapy Perspectives, 23, 18-28, http://dx.doi.org/10.1093/mtp/23.1.18.

Okun, B. F., \& Kantrowitz, R. E. (2014). Effective helping: Interviewing and counseling techniques (8th ed.). Stanford, CT: Cengage Learning.

Pitts, S. E., \& Cevasco, A. M. (2013). A survey of music therapy students' practica experiences in hospice and palliative care settings. Music Therapy Perspectives, 31, 144-156, https://dx.doi.org/10.1093/mtp/31.2.144.

Pitts, S. E., \& Silverman, M. J. (2015). Effects of verbal processing on psychiatric patients' proactive coping skills using recreational music therapy. Journal of Creativity in Mental Health, 10, 181-199, http://dx.doi.org/10.1080/15401383.2014.984097.

Ridley, C. R., Mollen, D., \& Kelly, S. M. (2011). Beyond microskills: Toward a model of counseling competence. The Counseling Psychologist, 39, 825-864, https://dx.doi.org/ 10.1177/0011000010378440.

Salmon, D. (2008). Bridging music and psychoanalytic therapy. Voices: A World Forum for Music Therapy, 8(1), http://dx.doi.org/10.15845/voices.v8i1.450.

Schönrock-Adema, J., Van der Molen, H. T., \& van der Zee, K. (2009). Effectiveness of a selfinstruction program for microcounseling skills training. Teaching of Psychology, 36, 246-252, https://dx.doi.org/10.1080/00986280903173132. 
Silverman, M. J. (2009). The effect of single-session psychoeducational music therapy on verbalizations and perceptions in psychiatric patients. Journal of Music Therapy, 46, 105-131, https://dx.doi.org/10.1093/jmt/46.2.105.

Silverman, M. J. (2015). Music therapy in mental health for illness management and recovery. Oxford: Oxford University Press.

Thompson, S., Grocke, D., \& Dileo, C. (2016). The use of group descriptive phenomenology within a mixed methods study to understand the experience of music therapy for women with breast cancer. Nordic Journal of Music Therapy, Advance online publication, https://dx.doi.org/10.1080/08098131.2016.1239648.

Sundar, S. (2008). Addressing diversities in music therapy theory, practice and research: Major challenges. Voices: A World Forum for Music Therapy, 7(1), http://dx.doi.org/10.15845/ voices.v7i1.468.

Vega, V. P., \& Keith, D. (2012). A survey of online courses in music therapy. Music Therapy Perspectives, 30, 176-182, https://dx.doi.org/10.1093/mtp/30.2.176.

Wheeler, B. L. (1983). A psychotherapeutic classification of music therapy practices: A continuum of procedures. Music Therapy Perspectives, https://dx.doi.org/10.1093/mtp/ 1.2.8.

Wheeler, B. L. (1987). Levels of therapy: The classification of music. Music Therapy, 6, 39-49, https://dx.doi.org/10.1093/mt/6.2.39.

Wylie, M. E., Hunter, B., \& Snell, A. (2013). Voices of the MLE: A 2013 review, Retrieved from, http://www.musictherapy.org/assets/1/16/2013_MLE_Subcommittee_Presents.pdf.

Young, L. (2016). Multicultural musical competence in music therapy. Music Therapy Perspectives, Advance online publication, https://dx.doi.org/10.1093/mtp/miw016. 